\title{
Rubazonic acids and their synthesis
}

My Linh Tong, Lena Theresa Leusch, Kristina Holzschneider and Stefan F. Kirsch*[a]

${ }^{a}$ Organic Chemistry, Bergische Universität Wuppertal, Gaußstr. 20, 42119 Wuppertal, Germany

sfkirsch@uni-wuppertal.de

\section{Supporting Information}

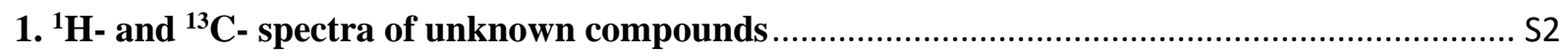

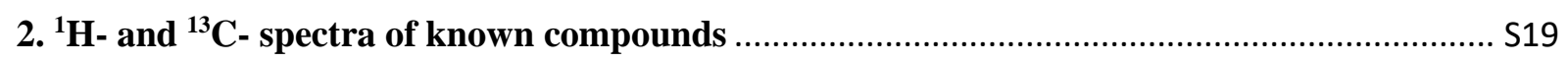




\section{1. ${ }^{1} \mathrm{H}$ - and ${ }^{13} \mathrm{C}$ - spectra of unknown compounds}
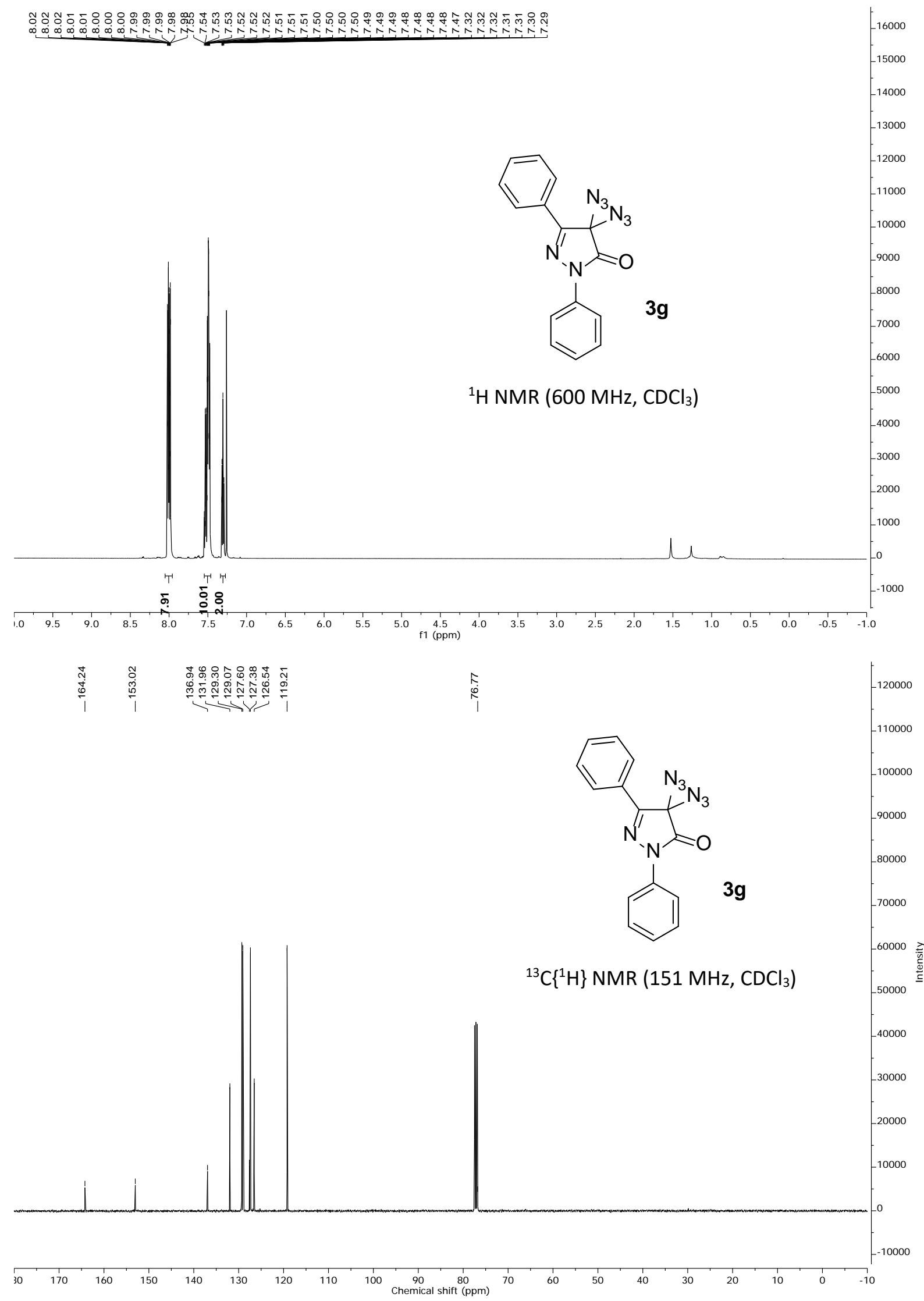
<smiles>NC1(N)C(=O)NN=C1c1ccccc1</smiles>

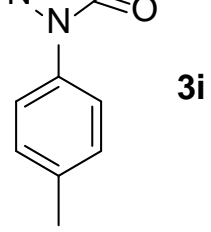

${ }^{1} \mathrm{H} \mathrm{NMR}\left(600 \mathrm{MHz}, \mathrm{CDCl}_{3}\right)$
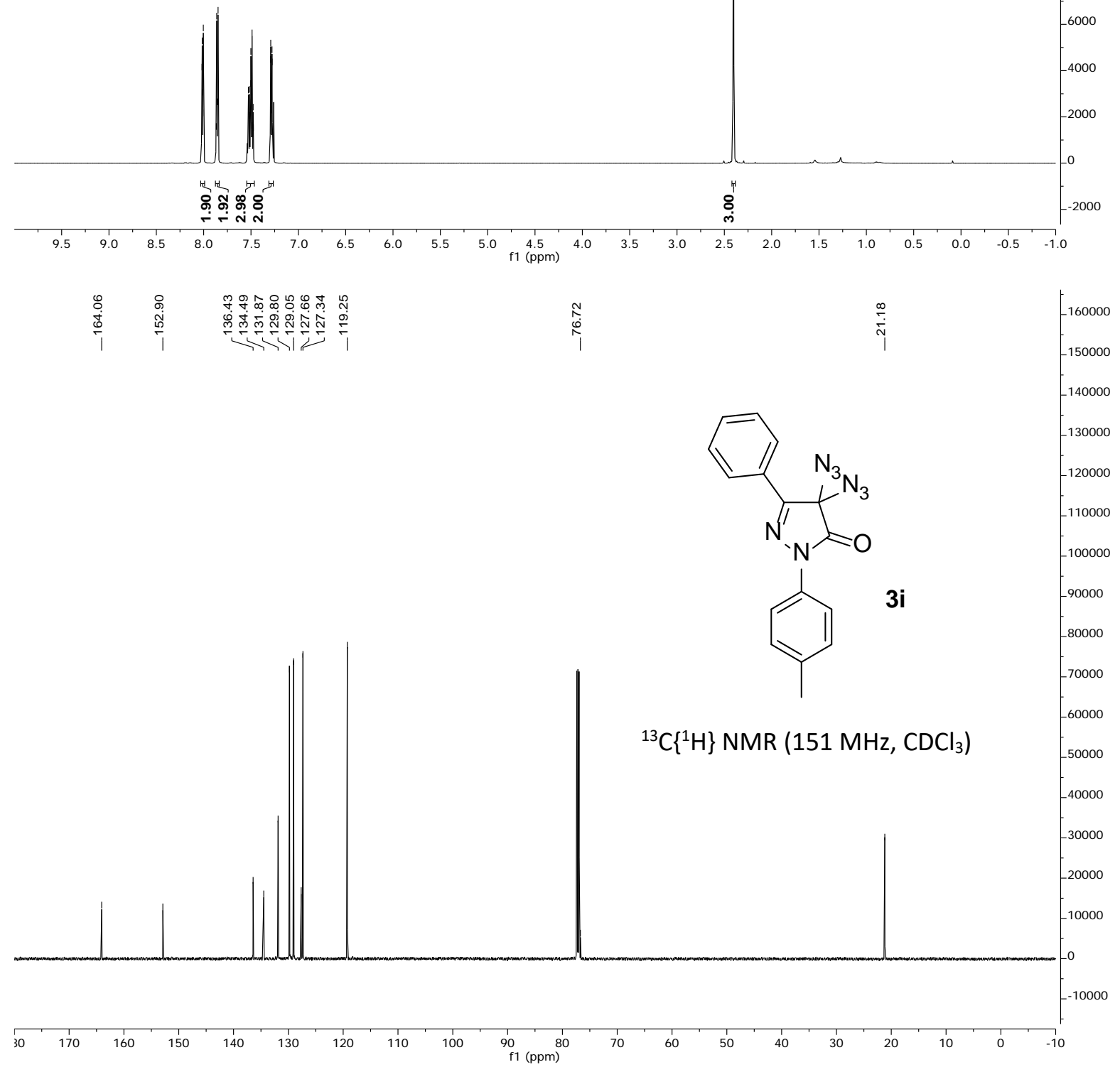


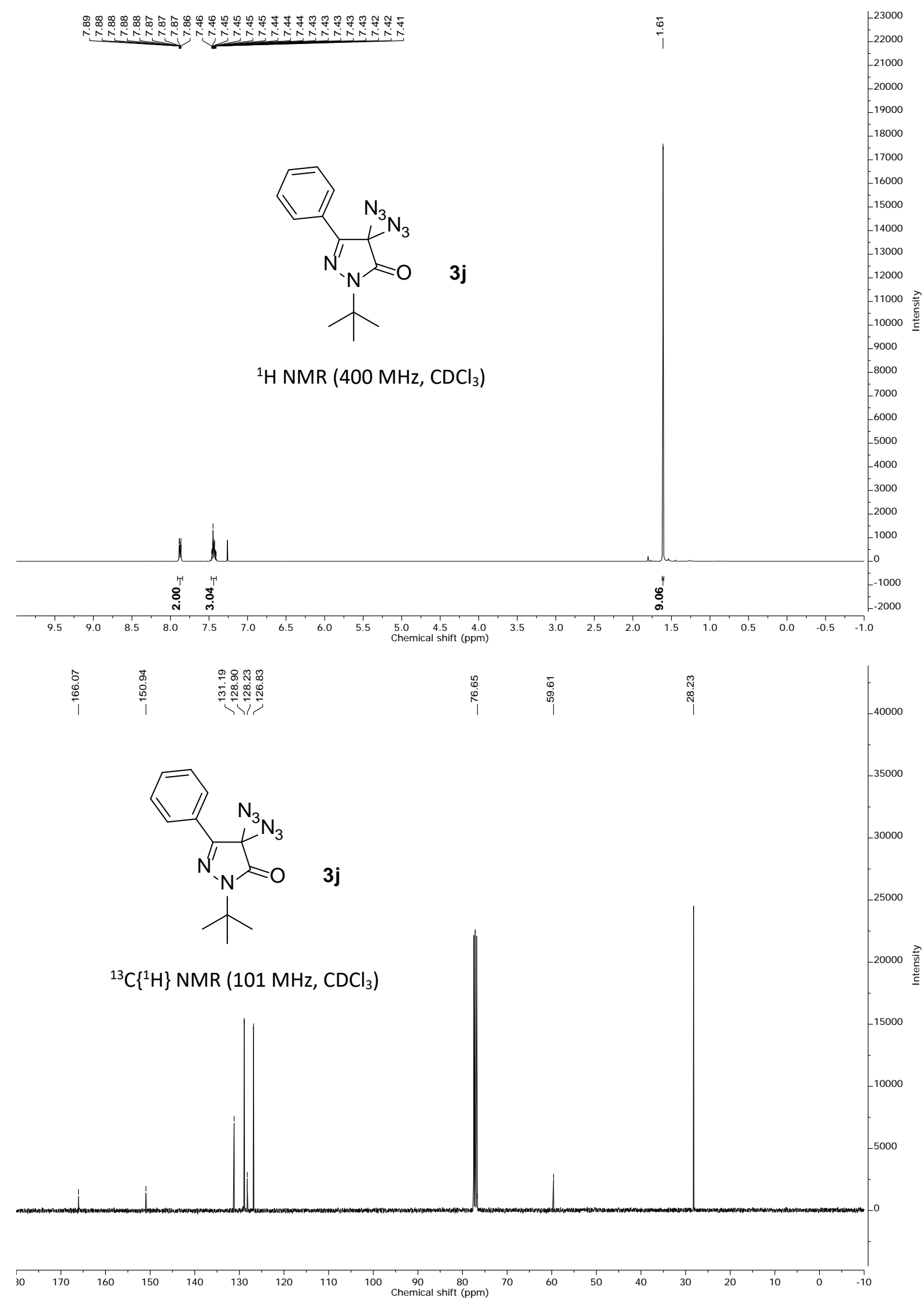


<smiles></smiles>

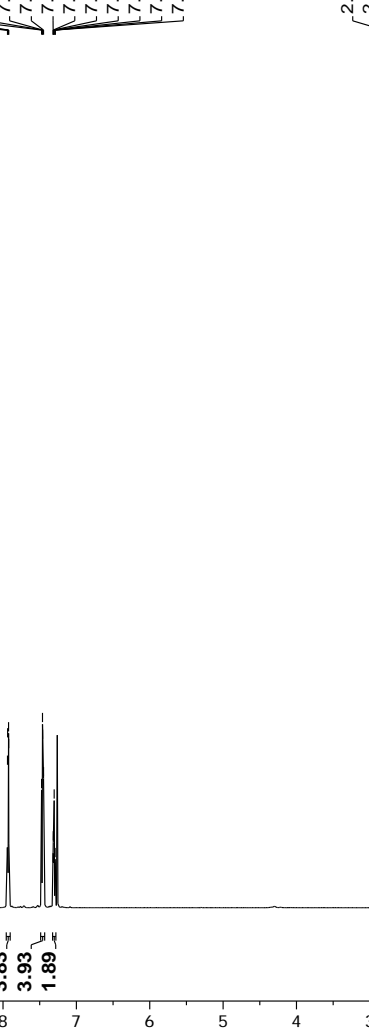

${ }^{1} \mathrm{H} \mathrm{NMR}\left(600 \mathrm{MHz}, \mathrm{CDCl}_{3}\right)$

1b

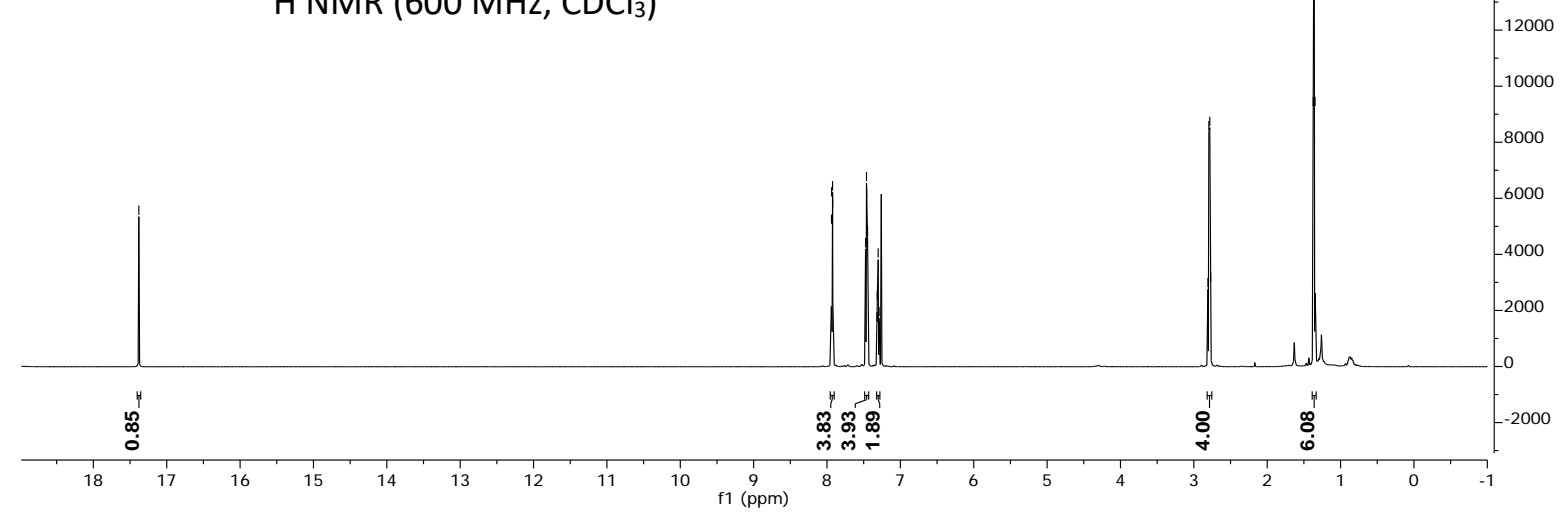

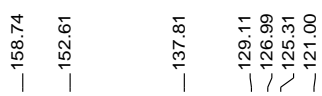<smiles></smiles>

$1 b$

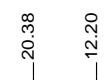

\begin{tabular}{|l}
\hline $1 / 1000$ \\
\hline-150000 \\
\hline-140000 \\
\hline-130000 \\
\hline-120000 \\
\hline-110000 \\
\hline-100000 \\
\hline-90000 \\
\hline-80000 \\
\hline-70000 \\
\hline 60000 \\
\hline-50000 \\
\hline-40000 \\
\hline-30000 \\
\hline-20000 \\
\hline-10000 \\
\hline 0 \\
\hline-10000 \\
\hline
\end{tabular}

$30 \quad 170 \quad 160$

${ }^{13} \mathrm{C}\left\{{ }^{1} \mathrm{H}\right\}$ NMR (151 MHz, $\left.\mathrm{CDCl}_{3}\right)$

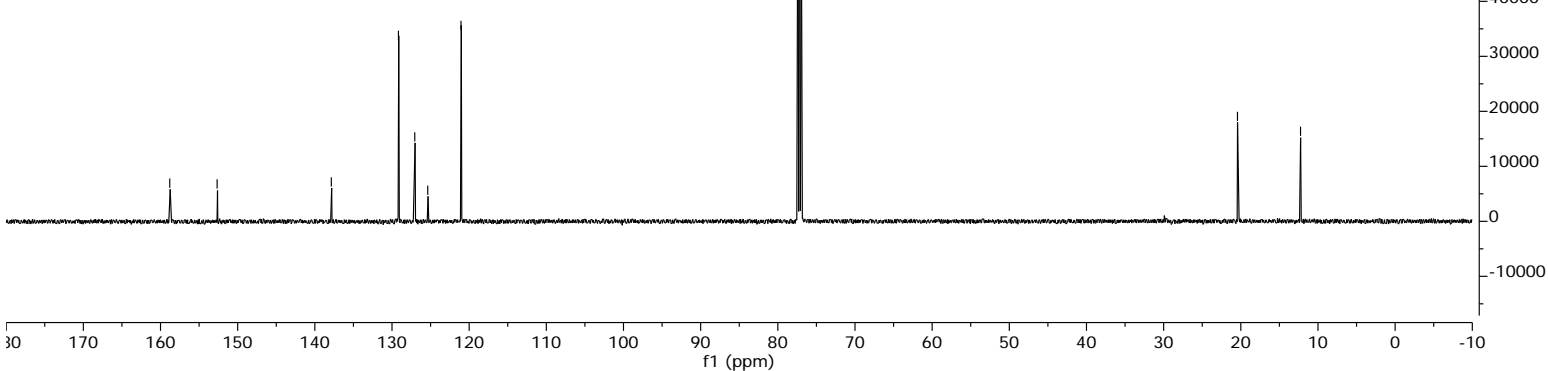




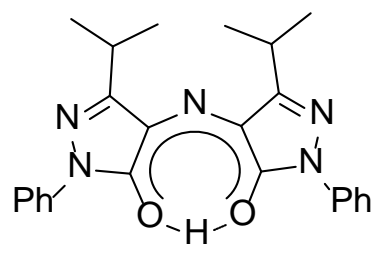

$1 c$

${ }^{1} \mathrm{H}$ NMR $\left(400 \mathrm{MHz}, \mathrm{CDCl}_{3}\right)$

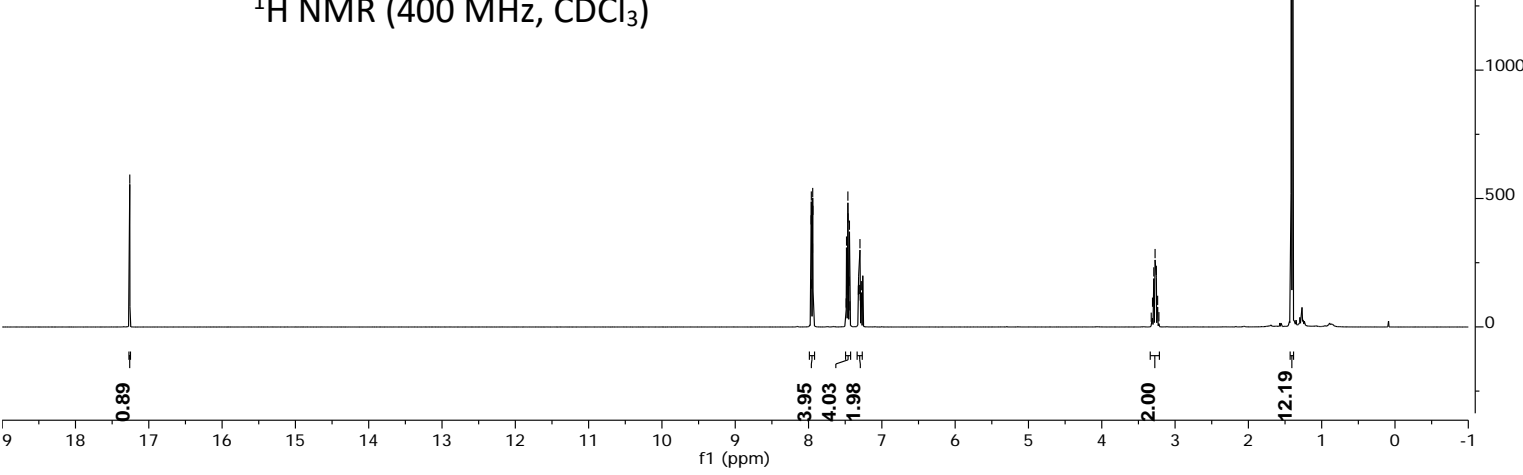

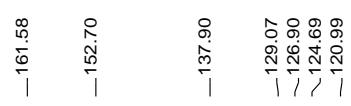

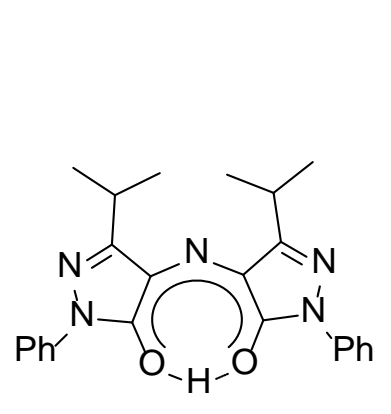

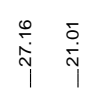




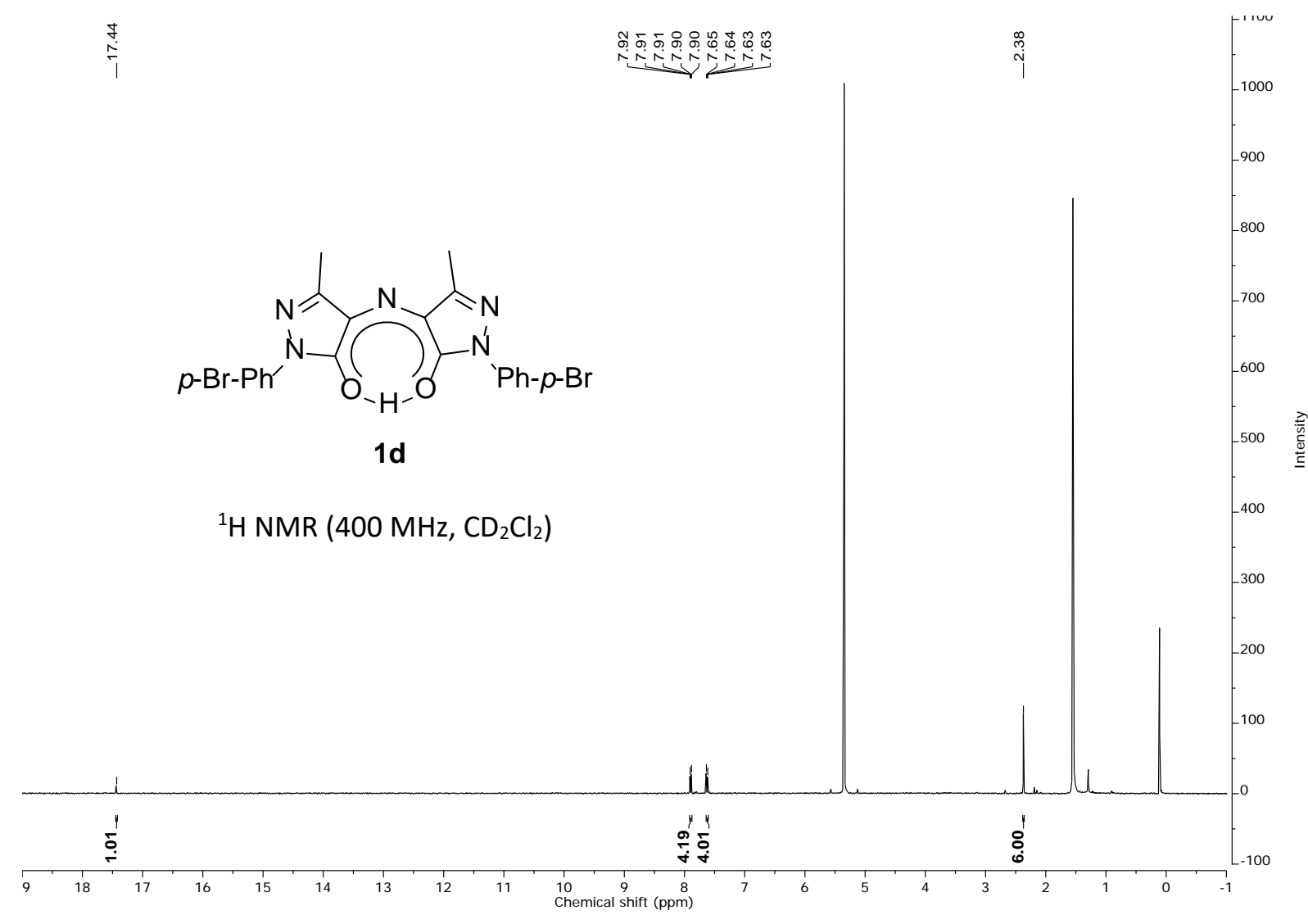

Compound was too insoluble to record a ${ }^{13} \mathrm{C}$ NMR. 


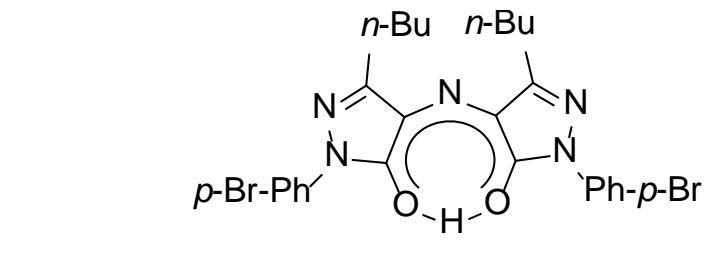

$1 \mathrm{e}$

${ }^{1} \mathrm{H}$ NMR $\left(400 \mathrm{MHz}, \mathrm{CDCl}_{3}\right)$

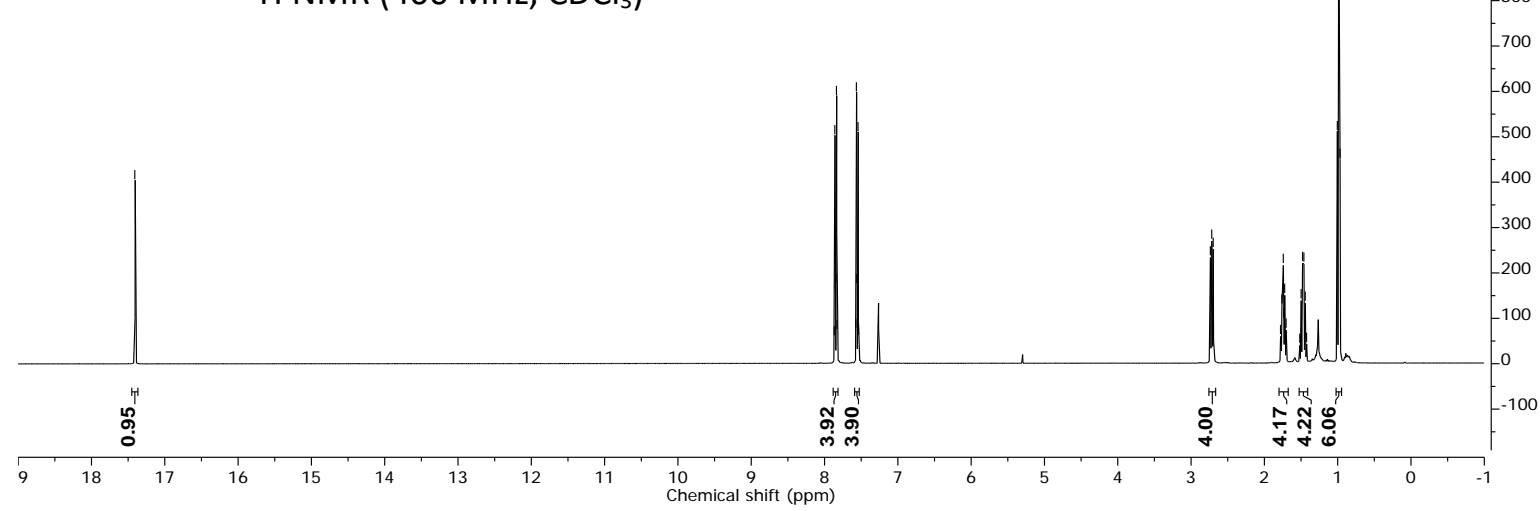

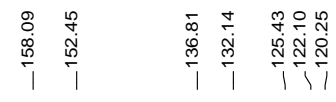

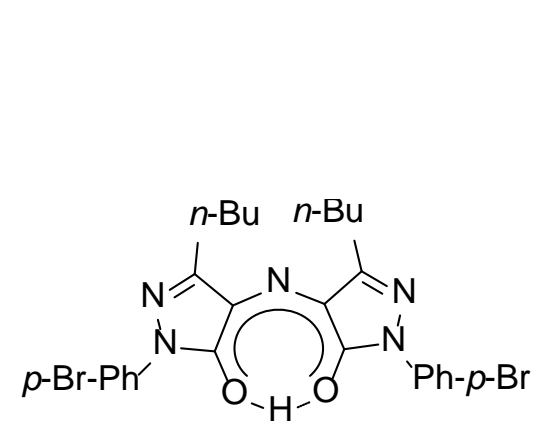

$-260000$

$$
1 e
$$

${ }^{13} \mathrm{C}\left\{{ }^{1} \mathrm{H}\right\}$ NMR $\left(101 \mathrm{MHz}, \mathrm{CDCl}_{3}\right)$

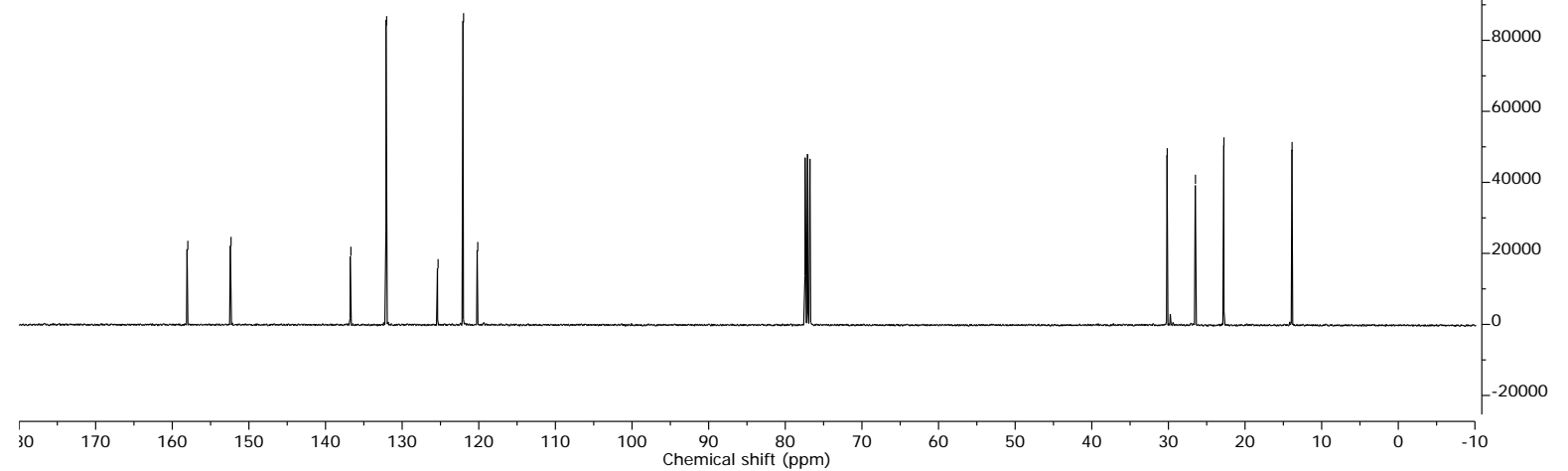




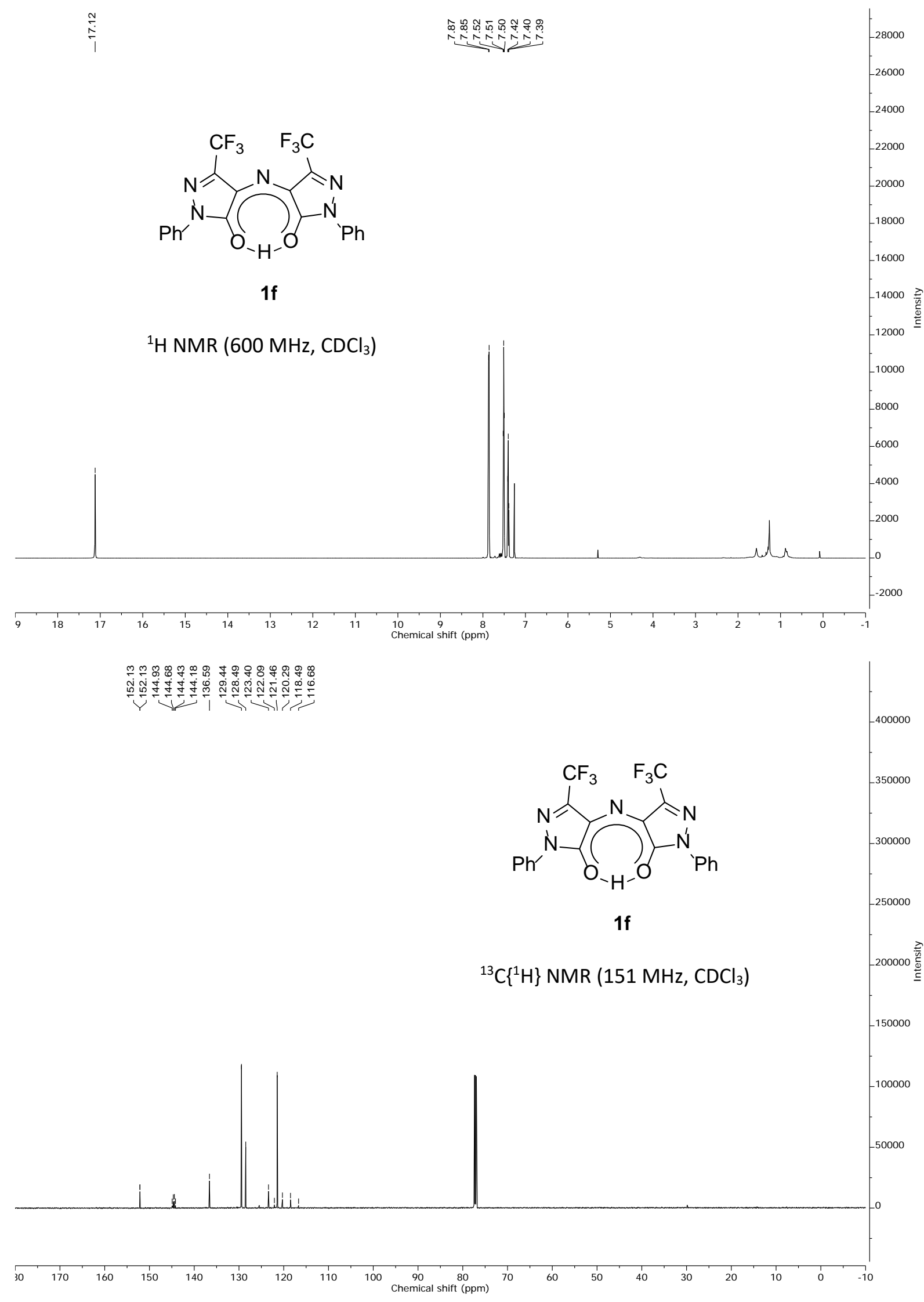




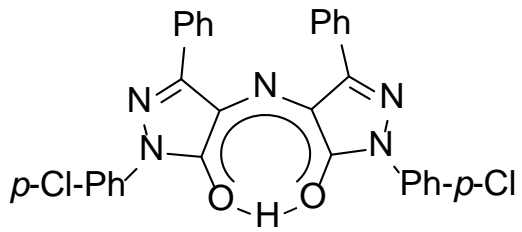

1h

${ }^{1} \mathrm{H}$ NMR $\left(400 \mathrm{MHz}, \mathrm{CDCl}_{3}\right)$

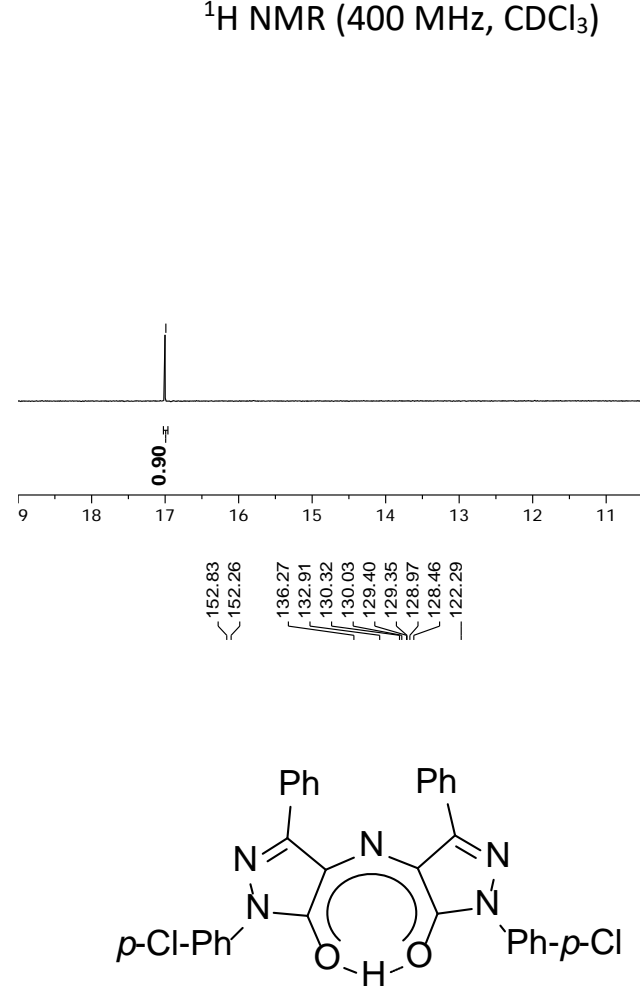

1h

${ }^{13} \mathrm{C}\left\{{ }^{1} \mathrm{H}\right\}$ NMR $\left(101 \mathrm{MHz}, \mathrm{CDCl}_{3}\right)$
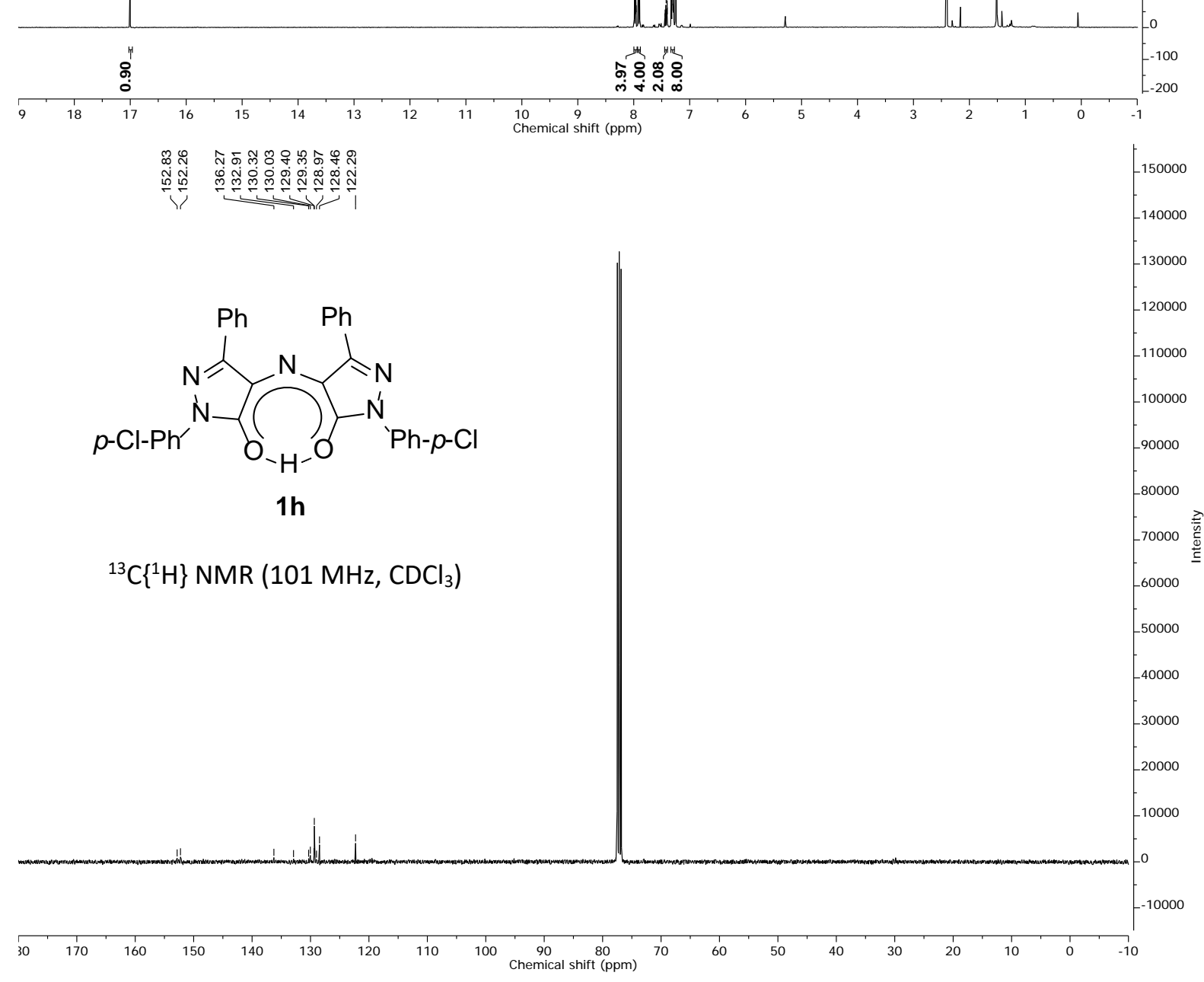

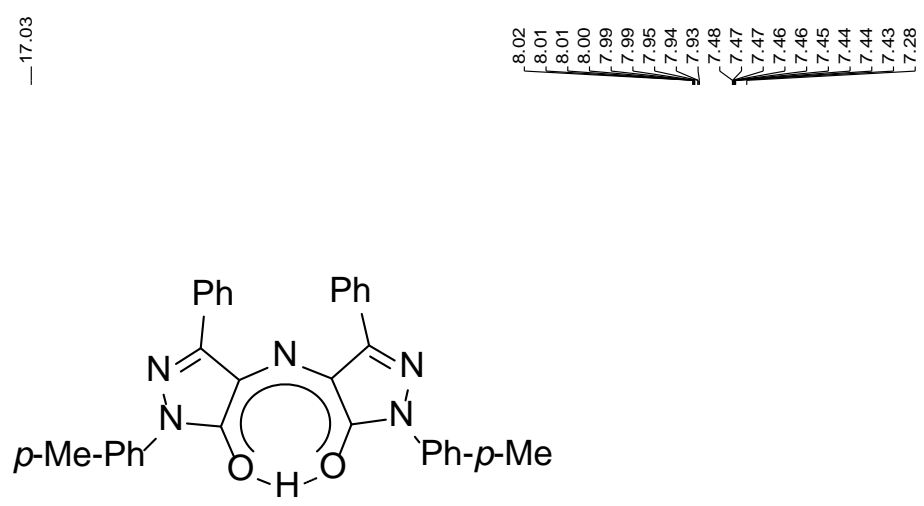

$1 \mathrm{i}$

${ }^{1} \mathrm{H}$ NMR $\left(400 \mathrm{MHz}, \mathrm{CDCl}_{3}\right)$

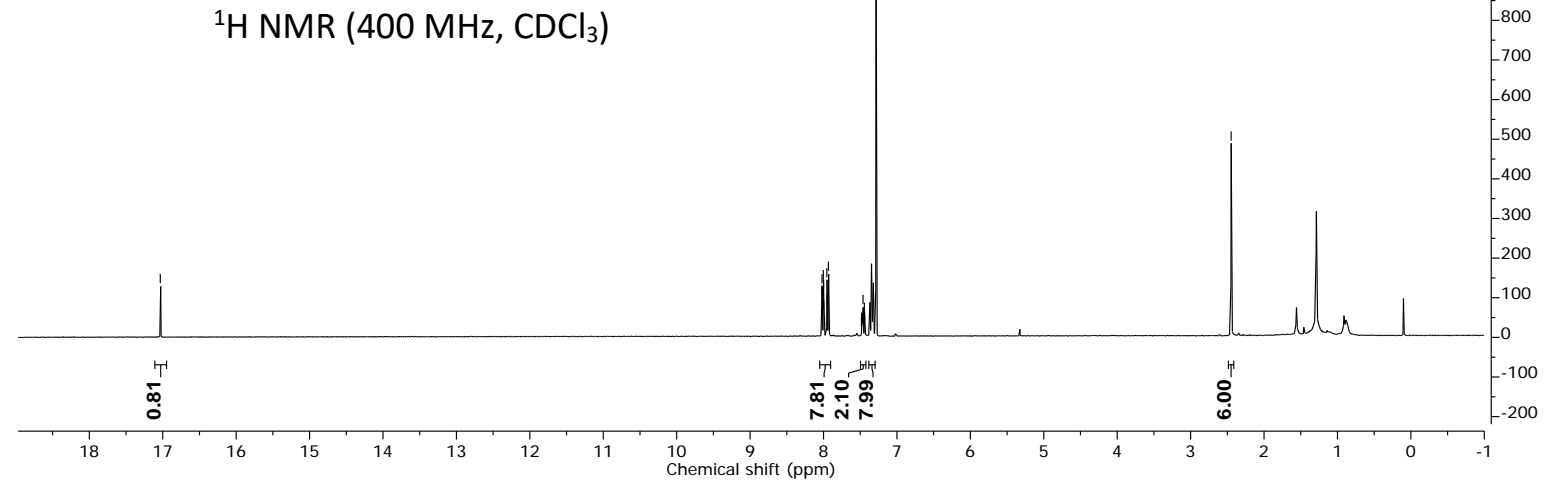

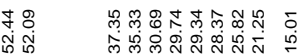

సูำ

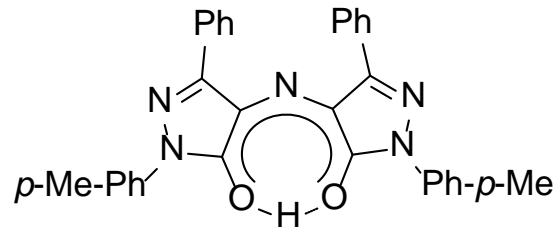

$1 \mathrm{i}$

${ }^{13} \mathrm{C}\left\{{ }^{1} \mathrm{H}\right\}$ NMR (101 MHz, $\left.\mathrm{CDCl}_{3}\right)$

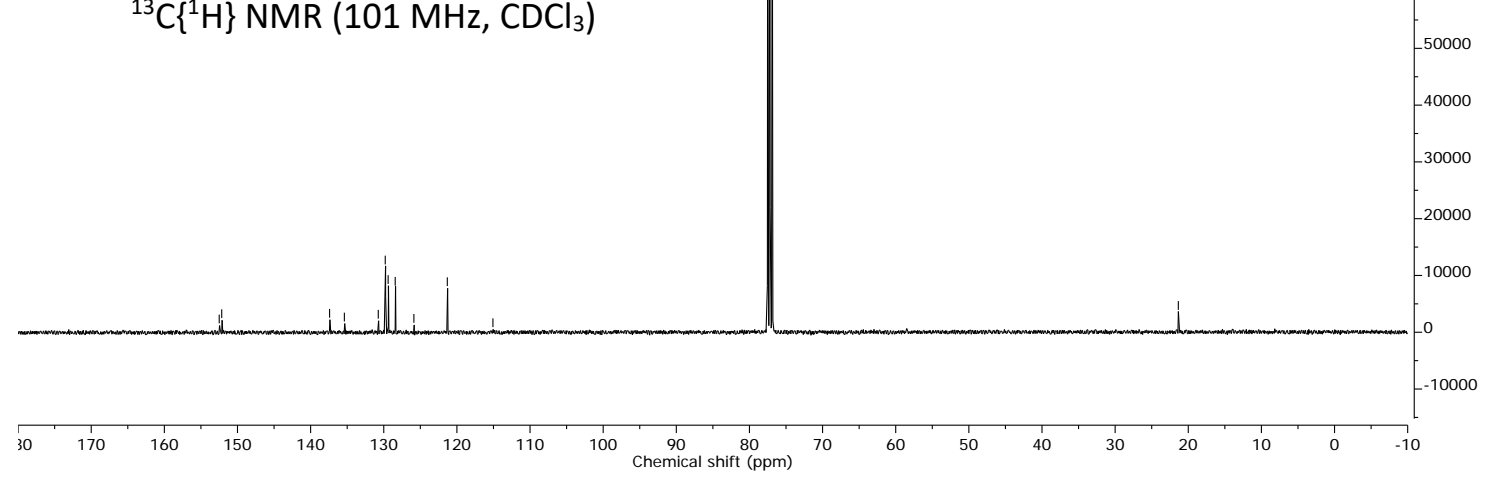




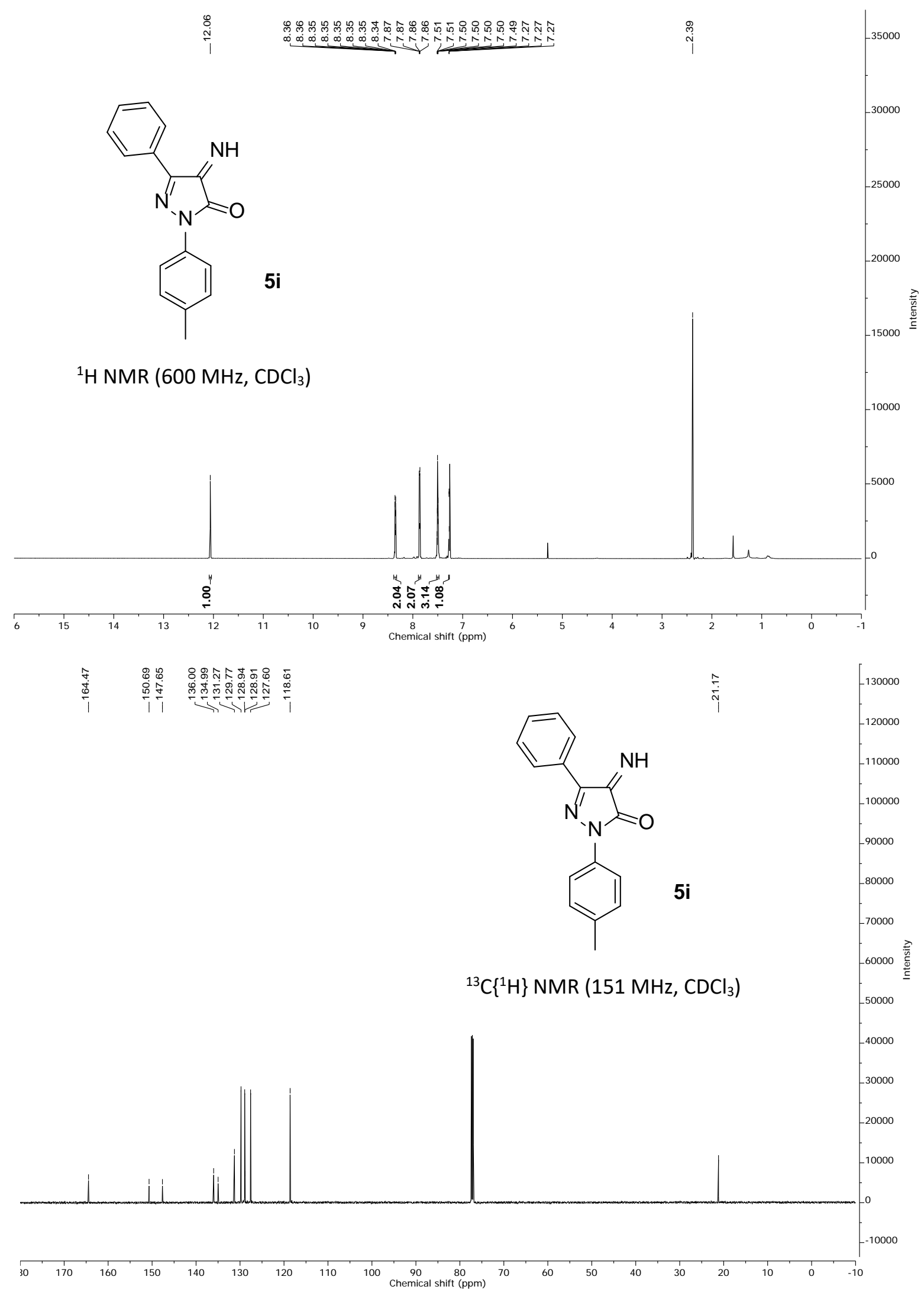




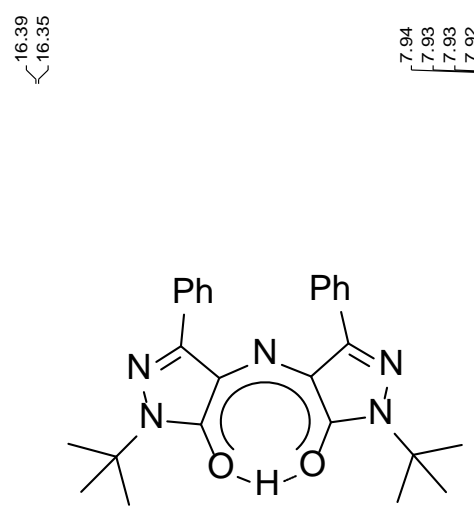

1j

${ }^{1} \mathrm{H}$ NMR $\left(400 \mathrm{MHz}, \mathrm{CDCl}_{3}\right)$
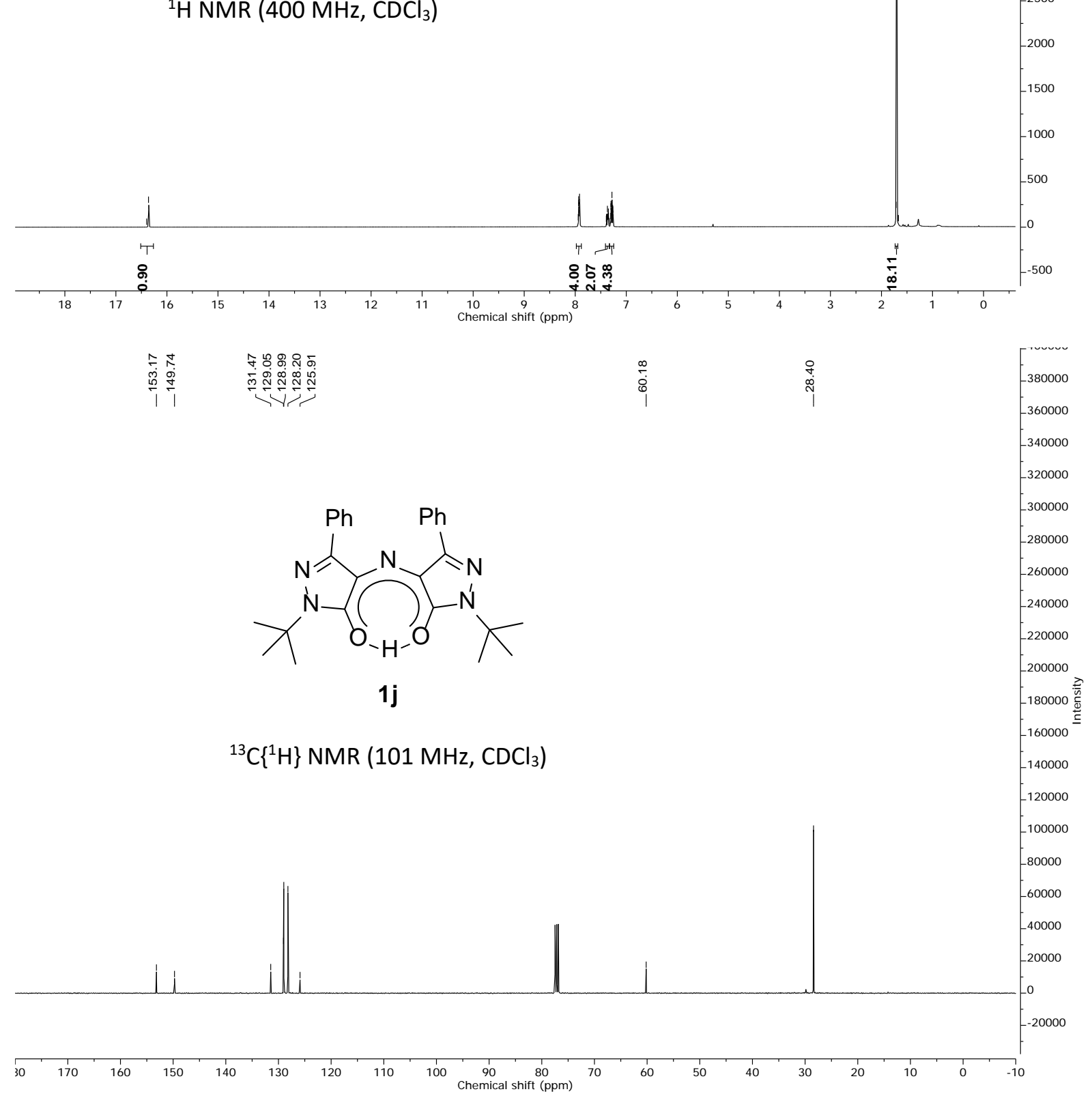


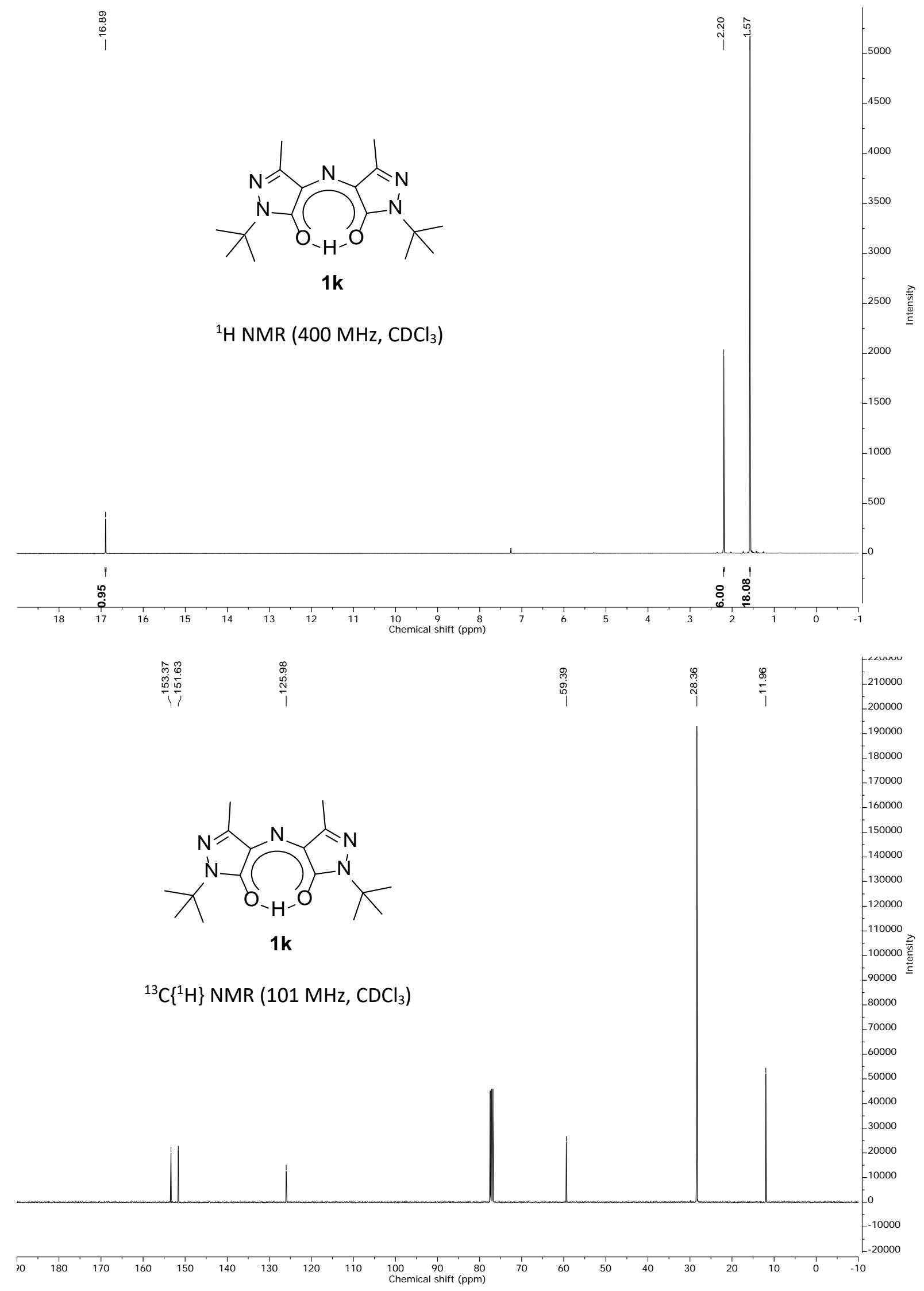


$\stackrel{\stackrel{N}{N}}{\stackrel{1}{1}}$<smiles>CCCC1=NC(=O)C(N=C2C(=O)N(C)N=C2CCC)=NC1=O</smiles>

1

${ }^{1} \mathrm{H} \mathrm{NMR}\left(600 \mathrm{MHz}, \mathrm{CDCl}_{3}\right)$

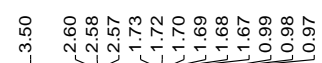

$-36000$

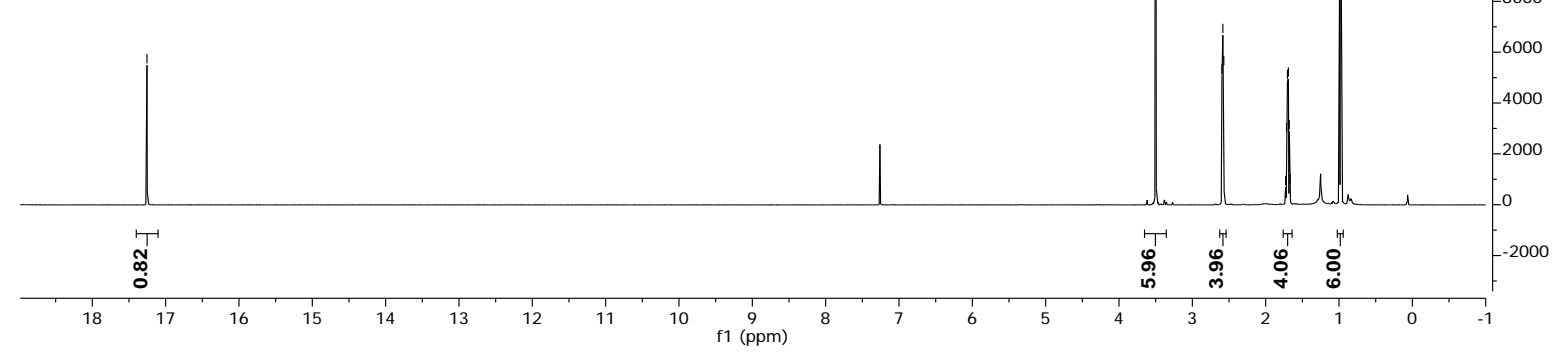

I

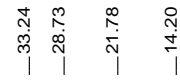

260000

240000

220000

200000<smiles>CCCC1=NC(=O)C(N=C2C(=O)N(C)N=C2CCC)=N1</smiles>

80000

60000

40000

$-120000$

11

100000

80000

${ }^{13} \mathrm{C}\left\{{ }^{1} \mathrm{H}\right\}$ NMR $\left(151 \mathrm{MHz}, \mathrm{CDCl}_{3}\right)$

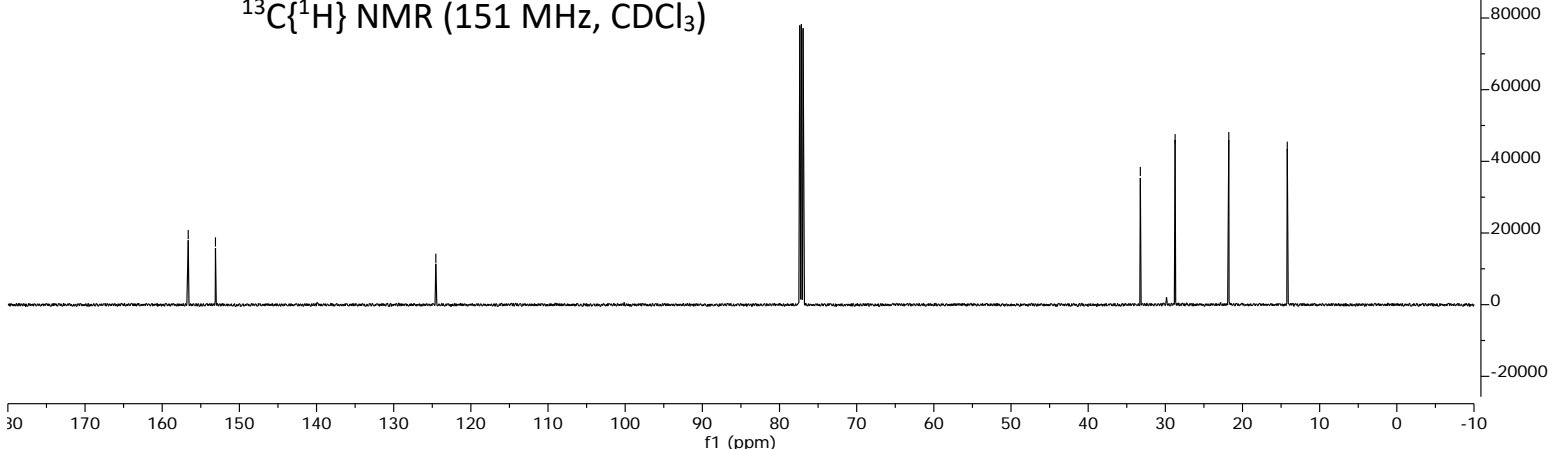


$\underset{\substack{0 \\ 0 \\ 1}}{1}$<smiles></smiles>

$1 \mathrm{~m}$

${ }^{1} \mathrm{H}$ NMR (400 MHz, $\mathrm{CDCl}_{3}$ )

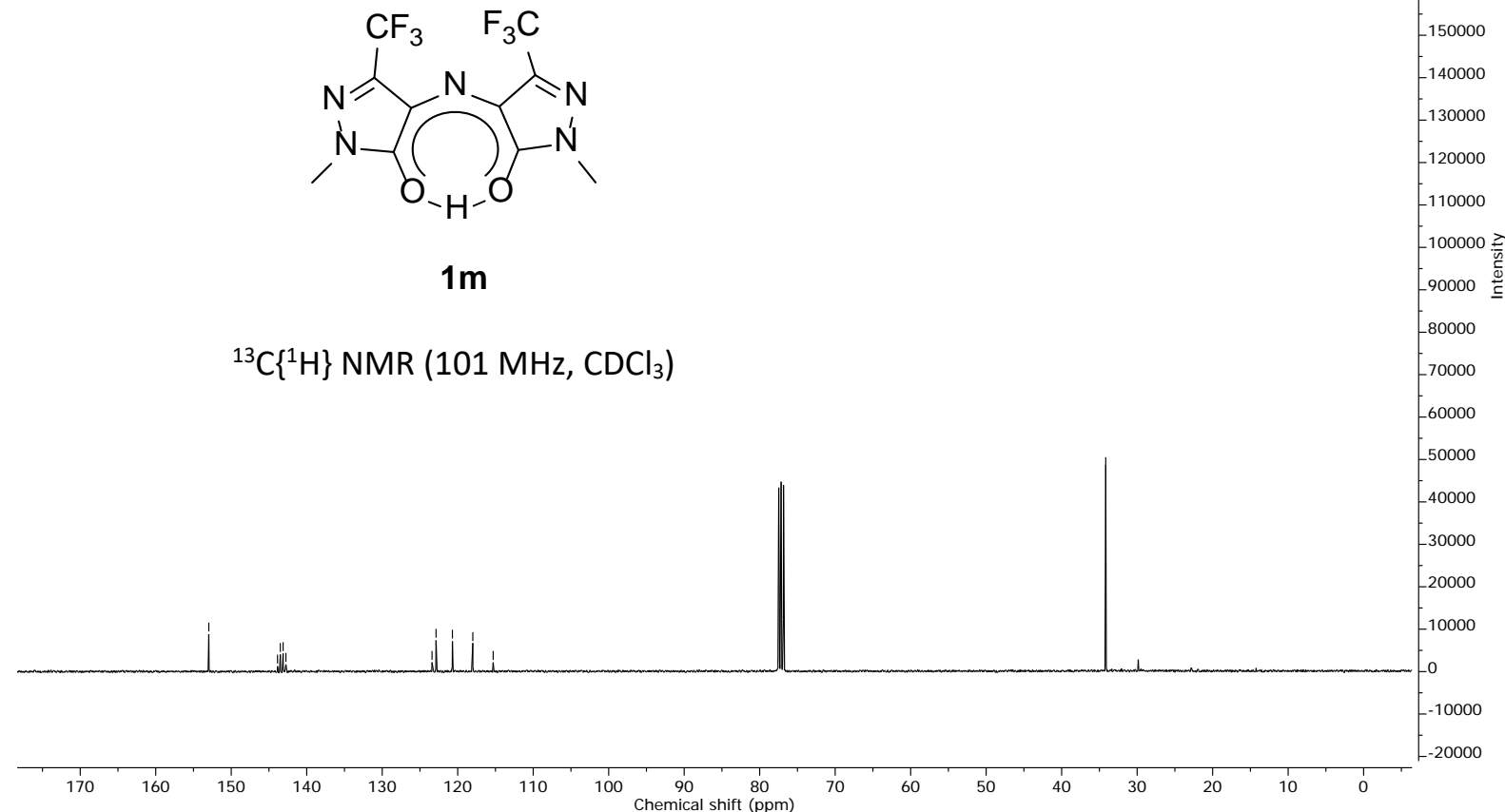

$1 m$

${ }^{13} \mathrm{C}\left\{{ }^{1} \mathrm{H}\right\}$ NMR $\left(101 \mathrm{MHz}, \mathrm{CDCl}_{3}\right)$

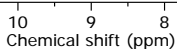

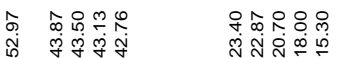

पन

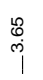

$-8500$

$-8000$

$-7500$

$-7000$

$-6500$

$-6000$

$-5500$

$-5000$

$-4500$

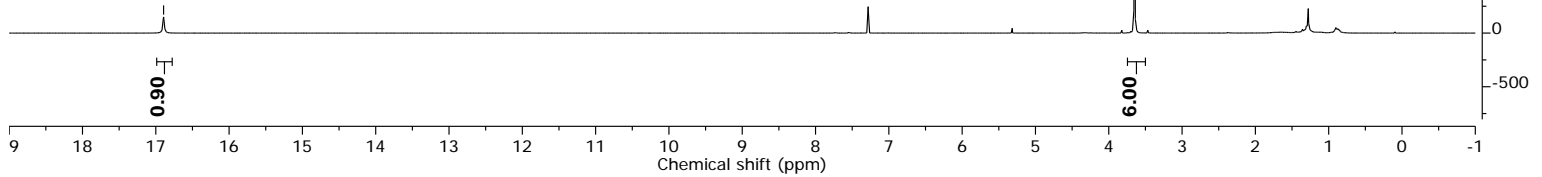




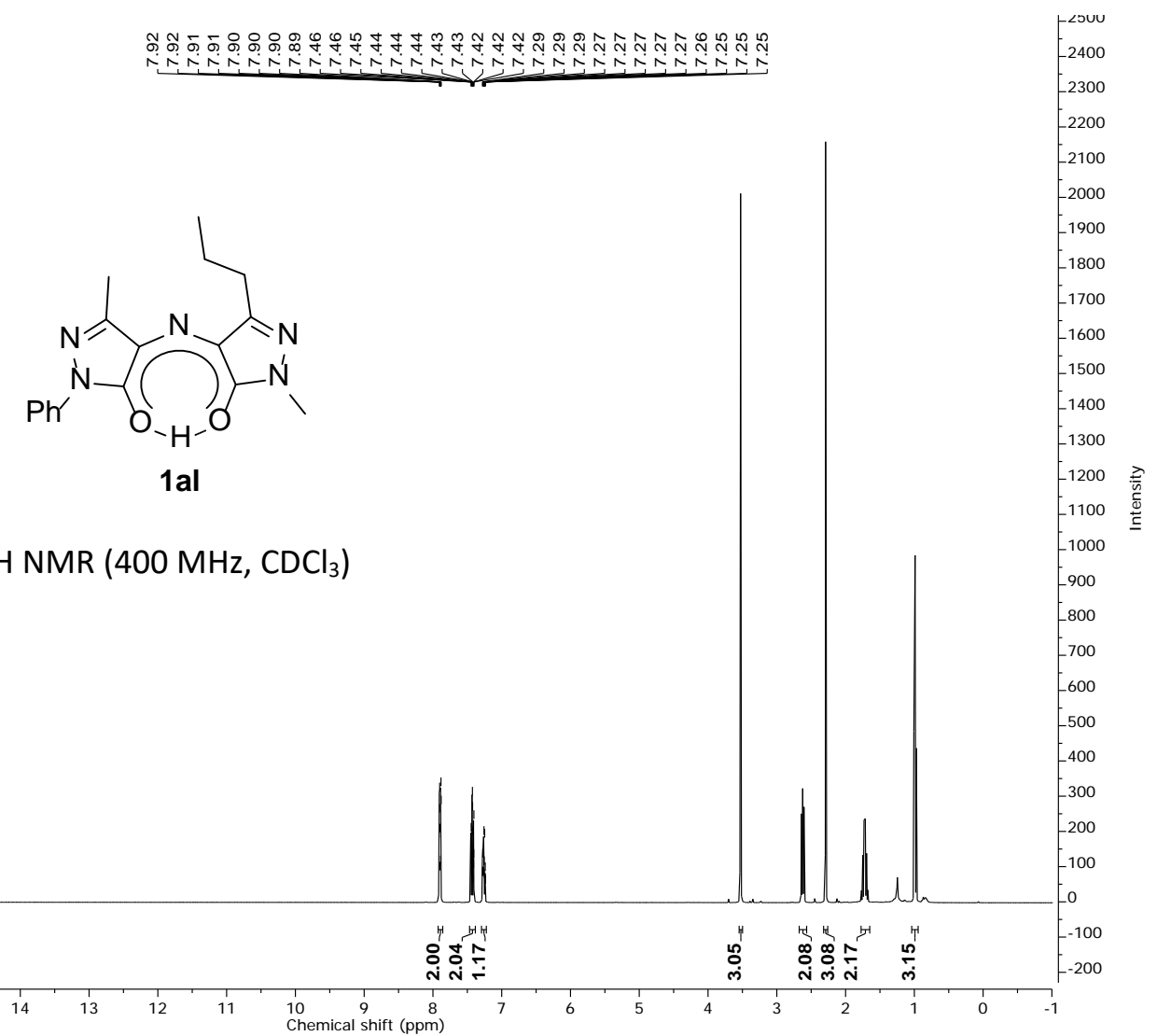

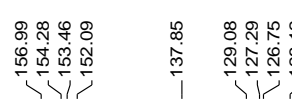

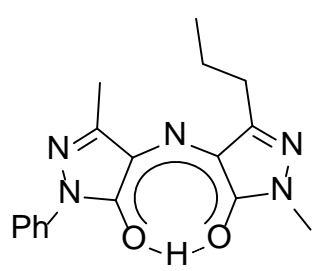

1al

${ }^{13} \mathrm{C}\left\{{ }^{1} \mathrm{H}\right\}$ NMR (101 MHz, $\left.\mathrm{CDCl}_{3}\right)$

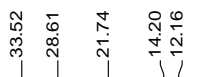

30000

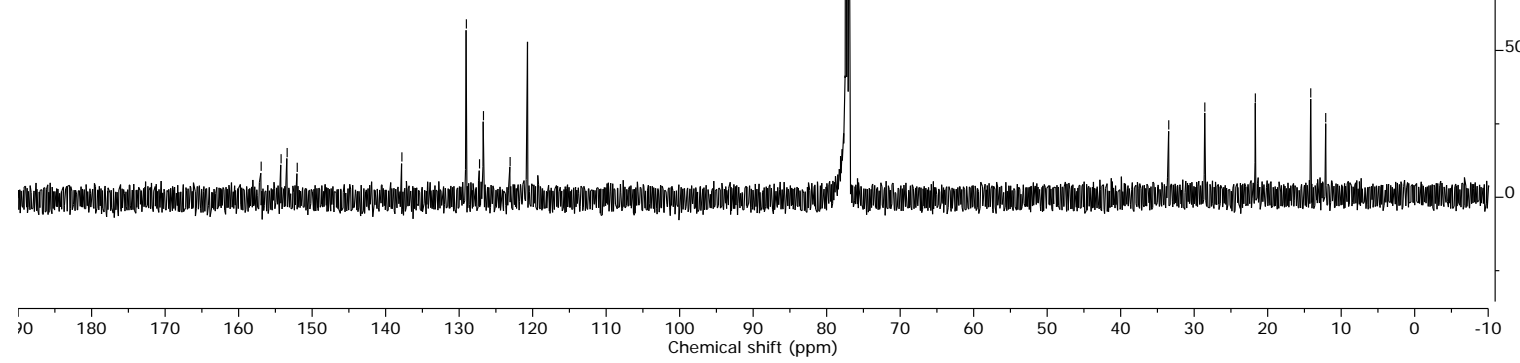




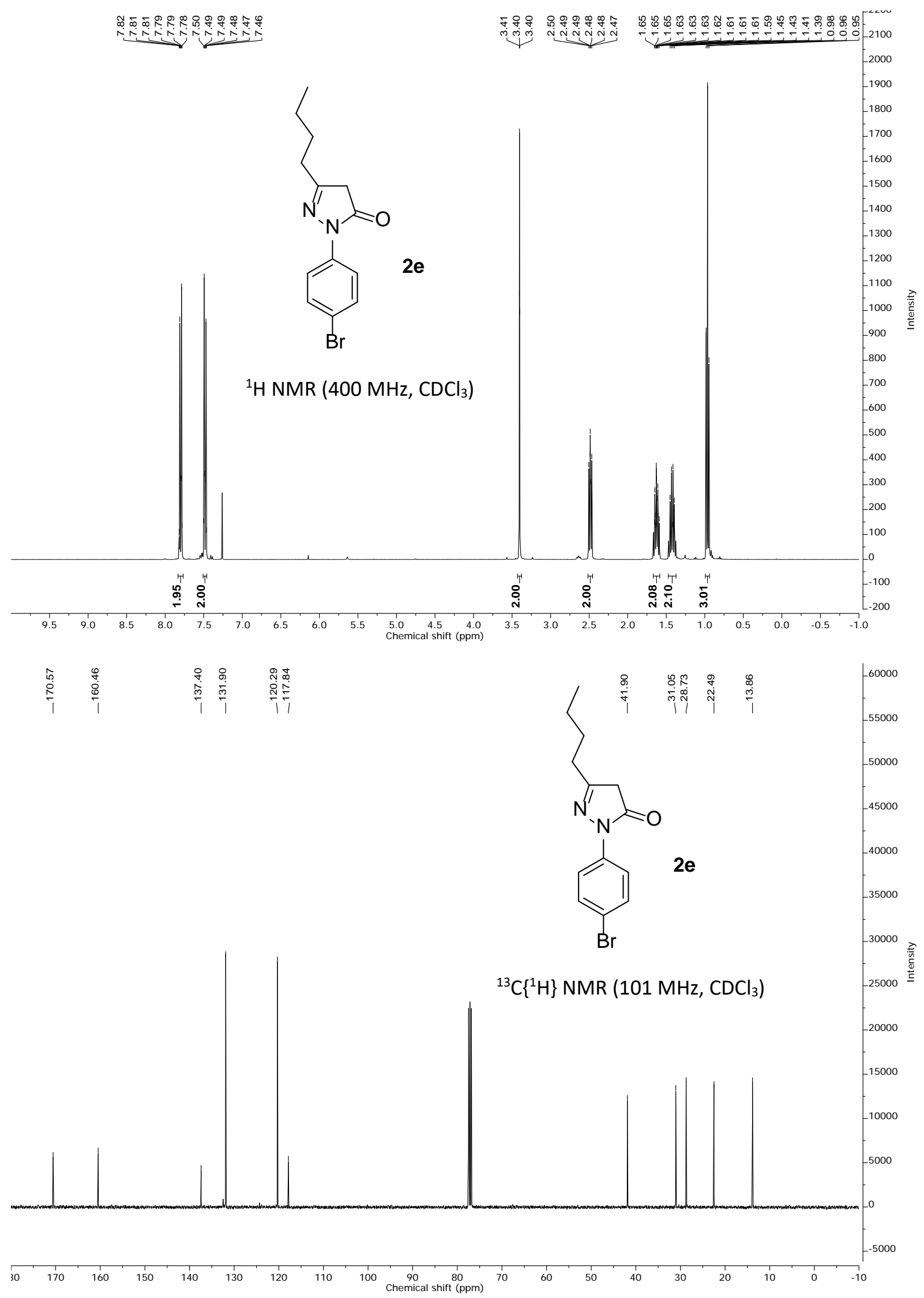




\section{2. ${ }^{1} \mathrm{H}$ - and ${ }^{13} \mathrm{C}$ - spectra of known compounds}

$\stackrel{7}{\stackrel{7}{~}}$
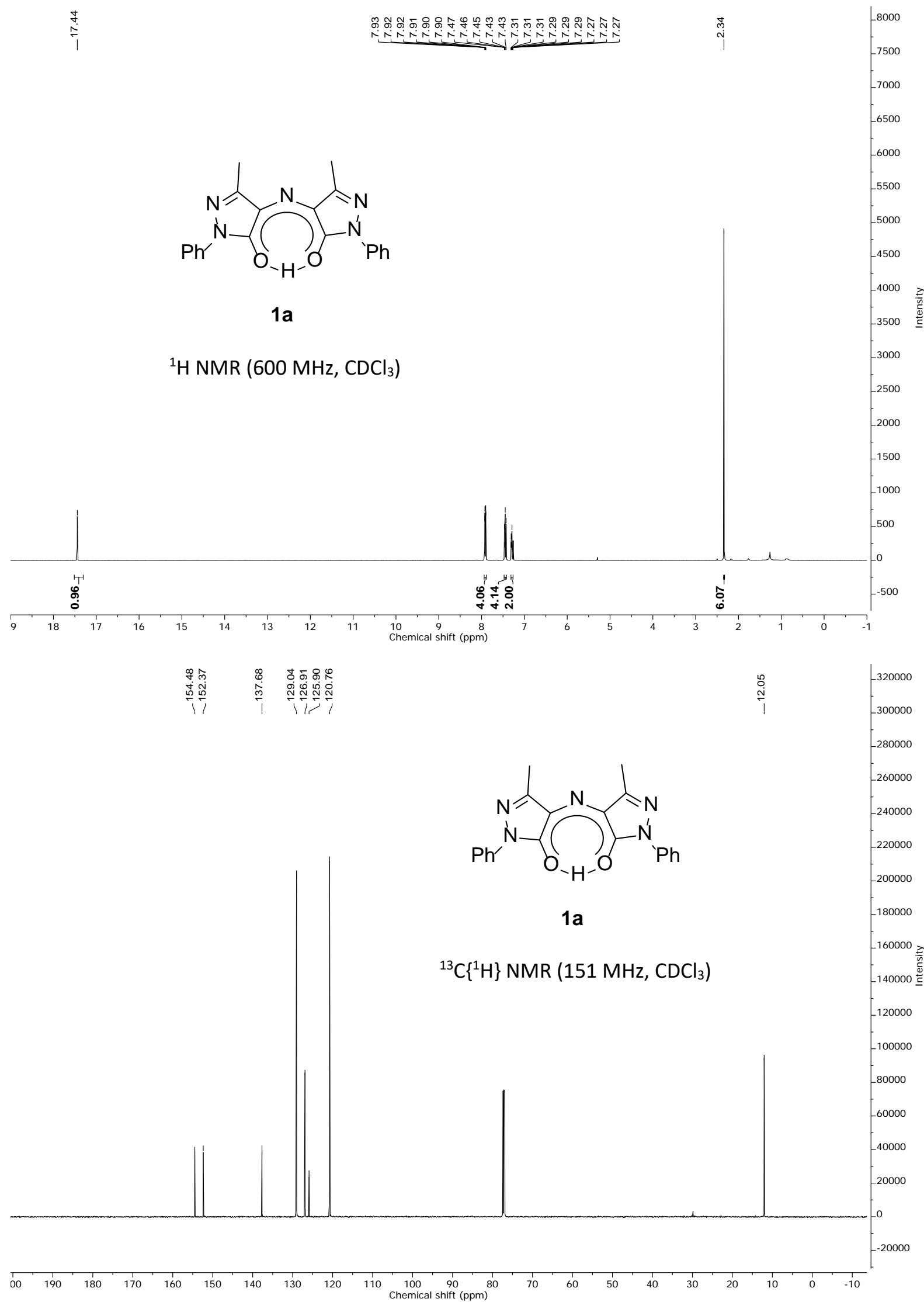


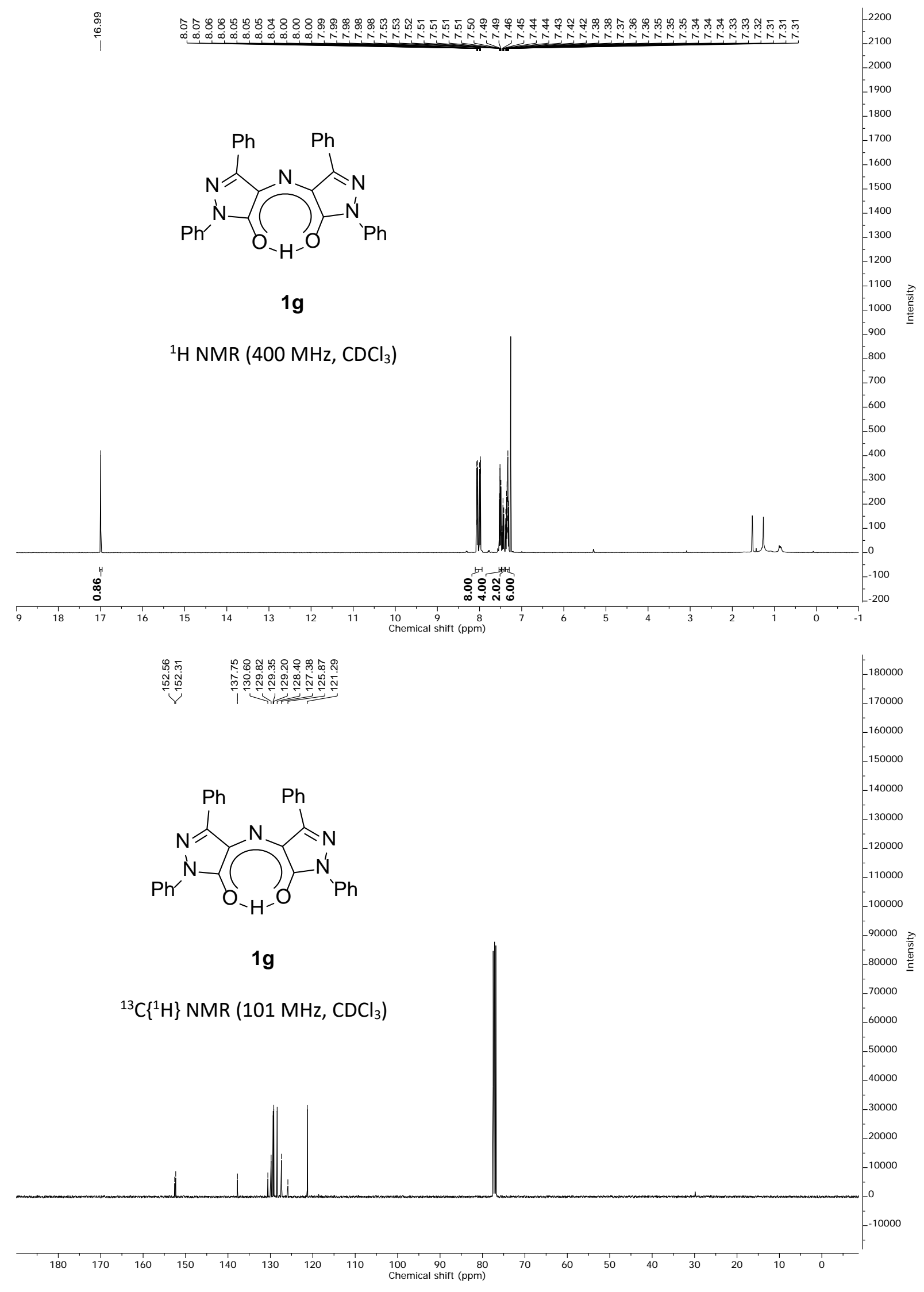

